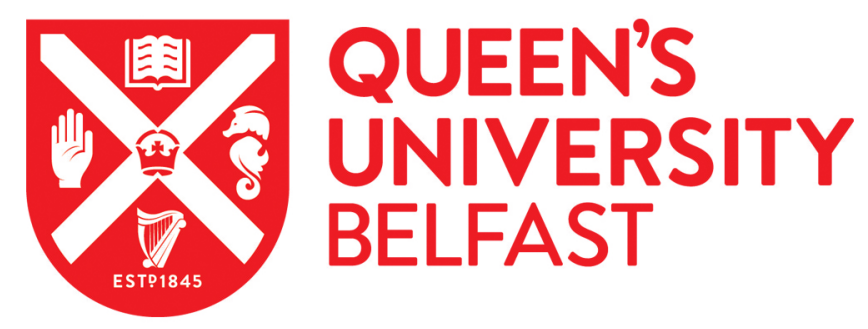

\title{
Optimisation of a two-liquid component pre-filled acrylic bone cement system: A design of experiments approach to optimise cement final properties
}

\author{
Clements, J., Walker, G., Pentlavalli, S., \& Dunne, N. (2014). Optimisation of a two-liquid component pre-filled \\ acrylic bone cement system: A design of experiments approach to optimise cement final properties. Journal of \\ Materials Science: Materials in Medicine, 25(10), 2287-2296. https://doi.org/10.1007/s10856-014-5260-y
}

Published in:

Journal of Materials Science: Materials in Medicine

Document Version:

Peer reviewed version

Queen's University Belfast - Research Portal:

Link to publication record in Queen's University Belfast Research Portal

Publisher rights

Copyright Springer Science+Business Media New York 2014.

The final publication is available at Springer via http://dx.doi.org/10.1007/s10856-014-5260-y.

\section{General rights}

Copyright for the publications made accessible via the Queen's University Belfast Research Portal is retained by the author(s) and / or other copyright owners and it is a condition of accessing these publications that users recognise and abide by the legal requirements associated with these rights.

\section{Take down policy}

The Research Portal is Queen's institutional repository that provides access to Queen's research output. Every effort has been made to ensure that content in the Research Portal does not infringe any person's rights, or applicable UK laws. If you discover content in the Research Portal that you believe breaches copyright or violates any law, please contact openaccess@qub.ac.uk. 


\section{Optimisation of a Two-Liquid Component Pre-Filled Acrylic Bone Cement}

System: A Design of Experiments Approach to Optimise Cement Final Properties

James. Clements ${ }^{1}$, Gavin. Walker ${ }^{2}$, Sreekanth Pentlavalli ${ }^{1}$, and Nicholas. Dunne ${ }^{1^{*}}$

${ }^{1}$ School of Mechanical and Aerospace Engineering, Queen's University Belfast, Stranmillis Road, Belfast, BT9 5AH, UK

${ }^{2}$ Department of Chemistry and Environmental Science, Plassey Park, University of Limerick, Limerick, Ireland

*Corresponding Author: $\quad$ Dr Nicholas Dunne

Email: $\quad$ n.dunne@qub.ac.uk

Telephone: $\quad$ +44 (0) 2890974122

Fax: $\quad$ +44 (0) 2890971144 


\section{Abstract}

The initial composition of acrylic bone cement along with the mixing and delivery technique used can influence its final properties and therefore its clinical success in vivo. The polymerisation of acrylic bone cement is complex with a number of processes happening simultaneously. Acrylic bone cement mixing and delivery systems have undergone several design changes in their advancement, although the cement constituents themselves have remained unchanged since they were first used. This study was carried out to determine the factors that had the greatest effect on the final properties of acrylic bone cement using a prefilled bone cement mixing and delivery system. A Design of Experiments (DoE) approach was used to determine the impact of the factors associated with this mixing and delivery method on the final properties of the cement produced. The DoE illustrated that all factors present within this study had a significant impact on the final properties of the cement. An optimum cement composition was hypothesised and tested. This optimum recipe produced cement with final mechanical and thermal properties within the clinical guidelines and stated by ISO 5833 (International Standard Organisation 2002), however the low setting times observed would not be clinically viable and could result in complications during the surgical technique. As a result further development would be required to improve the setting time of the cement in order for it to be deemed suitable for use in total joint replacement surgery. 


\section{Introduction}

During total joint replacement (TJR) surgery acrylic bone cement serves two main functions, firstly, fixation of the implant to bone and secondly, assisting in the transfer of mechanical loads between bone and femoral implant. Acrylic bone cement does not have any adhesives properties; it achieves these functions by acting as a grouting agent filling the space between bone and implant restricting movement. The large surface area created by the cement spreads loads uniformly, reducing stress concentrations on the bone during loading and joint movement.

The $9^{\text {th }}$ National Joint Registry for England and Wales (2011), reported 80,314 total hip procedures were carried out in this period, a 5\% increase from 2010. In the United States of America (USA) the incidence of total hip replacements (THR) are becoming increasingly common, with an expected increase of $174 \%$ by the year 2030. An increasing life expectancy, more active population and obesity are a number of reasons for increased procedures. For THR surgeries, approximately 50\% are carried out using cement fixation of the femoral implant. This method has proved to be successful with approximately $90 \%$ success rate after 15 years [1]. Revision THR surgeries account for about $12.4 \%$ of all hip procedure in the USA and of these $10.4 \%$ require further revision at some point [2].

Acrylic bone cement mixing and delivery systems have undergone several design changes in their advancement, although the cement constituents themselves have remained unchanged. It has been suggested that the process used to mix and deliver the cement may play a role in its clinical success in vivo [3]. The final cement properties can be directly influenced by the cement mixing and delivery technique used. Hand mixing the cement results in an increase in pores due to the introduction of air, which compromise the mechanical performance [3]. Lidgren et al (1984) demonstrated that using different cement mixing techniques proved to have an impact on the mechanical strength [4]. Dunne and Orr 
(2001) demonstrated that the mechanical performance of the cement improved as vacuum level applied during mixing increased [3]. Although bone cement is relatively strong in compression, it is weak in tension. It is accepted that cement fracture causing aseptic loosening plays a key role in the failure of TJR surgeries. The fatigue characteristics of bone cement are of paramount importance when considering the life expectancy of an implant due to it being subjected to millions of cyclic loads in vivo [5][6]. Hoey and Taylor (2009) demonstrated that cement mixed under a vacuum had a lower porosity, and as a result a higher fatigue life when compared to the same cement prepared by hand mixing [7]. The reduction in fatigue life of the hand mixed bone cement was attributed to a decrease in the load bearing area, and secondly pores within the cement microstructure acted as stress concentrations [7].

Due to the nature of the free radical polymerisation reaction, excess energy from the breaking of chemical bonds is released in the form of heat. It has been shown that exposing bone tissue to temperatures of $44-47^{\circ} \mathrm{C}$ for 1 minute will impair bone regeneration [8]. Bone tissue exposed to temperatures of $50^{\circ} \mathrm{C}$ for 1 minute or $47^{\circ} \mathrm{C}$ for 5 minutes have been shown not to function as normal bone tissue, but instead reabsorbed and be replaced by fat cells and tissue [8]. Literature suggests that $47^{\circ} \mathrm{C}$ is the threshold temperature that bone may be exposed to before necrosis occurs [9]. ISO 5833:2002 specifies that cement deemed for clinical use should exhibit a maximum temperature $\leq 90^{\circ} \mathrm{C}$ when tested in vitro, although this is higher than that implicated with thermal necrosis, temperature in vivo have been found to peak at $40-47^{\circ} \mathrm{C}[10][11]$. The effect of cement mantle volume along with the ambient temperature of mixing can influence this property. Meyer et al (1973) have shown that as the volume of the cement layer decreases the setting time and maximum temperature decreased, a trend was also shown with differences in ambient temperature [12]. An increase in ambient temperature from $4-37^{\circ} \mathrm{C}$ resulted in an increase in the maximum temperature of the cement 
from $53-125^{\circ} \mathrm{C}$. Turner et al (1982) reported that decreasing the temperature of the bone cement constituents prior to mixing resulted in smaller decay rates, but still first-order kinetics were observed. This decrease in decay rate with lower initial temperature may be caused by a reduction in cement porosity, potentially due to decreased monomer evaporation [13]. Other variables such as polymer powder: liquid monomer ratio have been studied, showing that higher powder: liquid monomer ratio resulted in shorter characteristic growth time of free radicals associated with polymerisation, hence a reduced setting time [14]. Other studies support the findings that setting temperature and volume of cement affect the amount of residual monomer in the polymerised cement which, in turn, influences the mechanical properties [15]. Shrinkage of the cement can occur during two phases of the cement formation process. It can occur as a consequence of polymerisation but also due to thermal shrinkage. Thermal shrinkage occurs in the latter stages of polymerisation when the cement has taken on a solid form, and can lead to the formation of residual thermal stresses within the cement mantle, which can result in microcracks forming within the cement mantle potentially resulting in premature failure of the cemented joint [16][17].

Traditional strategies for material development can be highly involved, requiring gradual iteration towards a target set of properties. Design of Experiments (DoE) allows a structured, statistically robust approach to materials development and generates predictive tools for determining optimal formulations from a minimum number of experiments. Recently the DoE approach has been used to understand the effects of variables when designing bone cement formulations for the application of vertebral body augmentation procedures [18] [19] [20].

Although acrylic bone cement has been used in cemented TJR surgical procedures for over 50 years, there are still issues associated with the quality of the bone cement mix produced in terms of reliability and consistency during mixing and delivery. Removal of 
variability from the cement mixing and delivery system may allow for a more consistent and reliable cement mix to be achieved, presenting an attractive proposition for the orthopaedic community. The aim of this investigation was two-fold: (i) apply a Design of Experiments (DoE) approach to understand the dominant factors that influence the performance of acrylic bone cement using a pre-filled mixing and delivery system and (ii) establish an alternative concept for mixing and delivery of acrylic bone cement based on optimisation of clinically relevant cement properties.

\section{Materials and Methods}

\subsection{Cement Preparation}

The acrylic bone cements was produced in this study using a pre-filled mixing and delivery system. Poly (methyl methacrylate) (PMMA) powder (Colacryl) of differing weight average molecular weight (MW) was used, EDP340 and EDP341 with MW of 80,000 and 120,000 g/mol respectively (Lucite International Ltd., UK). Methyl methacrylate (MMA), barium sulphate $\left(\mathrm{BaSO}_{4}\right), \mathrm{N}, \mathrm{N}$-dimethyl-p-toluidine (DmpT) and benzoyl peroxide (BPO) were all supplied by Sigma Aldrich UK. Cement mixes were prepared in a 200mL RatioPak ${ }^{\circledR}$ dual cartridge system (Ellsworth Adhesives Ltd., UK). Each barrel contained PMMA, MMA and $\mathrm{BaSO}_{4}$, with BPO and DmpT added to separate cartridge barrels. The cartridge barrels were then sealed and placed on a pair of co-rotating rollers, which rotated in the clockwise direction at a frequency of $0.5 \mathrm{~Hz}$ for $6-18 \mathrm{~h}$ depending on the experimental run. The rotating roller system was used to allow for full dissolution of PMMA powder into the monomer. Following the rotation phase, each cartridge was removed and stored in an upright position at $4^{\circ} \mathrm{C}$ for $30 \mathrm{~min}$, allowing air bubbles to rise to the surface. Cement mixing and injection was conducted using a Ratio-Pak ${ }^{\circledR}$ pneumatic dispensing gun (Ellsworth Adhesives Ltd., UK) and a Ratio-Pak ${ }^{\circledR}$ static mixer nozzle (Ellsworth Adhesives Ltd., UK). 
During injection, the two-paste components met in the static mixer nozzle, containing 24 static stepped mixing elements, and intertwined fully to allow BPO and DmpT to interact, initiating polymerisation and cement curing thereafter. This method of preparation allowed the two-paste components to be mixed and delivered via a single closed system, therefore removing operator variability associated with conventional cement mixing and delivery.

\subsection{Design of Experiments}

A Design of Experiments (DoE) approach was used to determine the effect of factors or interactions between factors on the particular parameters analysed. The DoE involved the use of a two-level fractional design using a $1 / 2$ fractional factorial (Design Expert V5 Software, Stat-Ease Inc, USA). There were five factors (A-E) included in the design methodology: (A) Powder Molecular Weight, (B) Powder to Liquid Ratio, (C) BPO Content, (D) DmpT Content and (E) Mixing Time, high and low levels were attributed to each factor (Table 1). The DoE created a fractional factorial producing 20 experimental runs. The DoE method allows for statistical analysis using the Analysis of Variance method (ANOVA) whereby a pvalue $<0.05$ is deemed a significant result. This was represented through a factor percentage contribution to the analysed parameter. A percentage contribution $\geq 10 \%$ was deemed to have a relatively major contribution on the parameter(s) being analysed in this study, which was in accordance with the Design Expert V5 Reference Manual (Stat-Ease Inc, USA).

\subsection{Characterisation Techniques}

Each experimental run was analysed in regards to their static and fatigue mechanical properties, thermal properties, porosity content and shrinkage levels. Analysis of static mechanical and thermal properties were conducted in accordance with ISO 5833:2002, Implants for Surgery - Acrylic Resin Cements [11]. The compressive properties of each bone cement mix were determined in accordance with ISO 5833:2002 (International Standard 
Organisation 2002) using a EZ50 Advanced Materials Testing System (Lloyd Instruments Ltd, UK) using a $1 \mathrm{kN}$ load cell, operating at a crosshead speed of $20 \mathrm{~mm} \mathrm{~min}^{-1}$. Each compressive sample was tested to failure and a load versus deformation plot recorded. A total of 6 specimens were tested for each bone cement mix. The bending strength and modulus for each cement mix was determined using a four point bending test arrangement. All bending tests were conducted using the EZ50 Advanced Materials Testing System (Lloyd Instruments Ltd, UK) using a $5 \mathrm{kN}$ load cell, which operated at a crosshead speed of $5.0 \mathrm{~mm} \mathrm{~min}^{-1}$. The load and deflection at mid-span were recorded to failure of each sample and the bending modulus and bending strength were calculated according to ISO 5833:2002. A total of 6 bone cement samples were tested for each cement mix.

The fatigue properties of each bone cement mix were assessed using a purpose built pneumatically controlled testing machine (Zwick-Roell, UK) and cycled continuously in load control until failure [5]. The study adopted a similar test protocol to that used by Harper and Bonfield [21]. The shape profile for the fatigue specimens was representative of the half sized ISO 527-2 multipurpose test specimen and the dimensions were $75 \pm 0.5 \mathrm{~mm}$ in length, $5 \pm$ $0.2 \mathrm{~mm}$ in width, approximately $3.5 \pm 0.2 \mathrm{~mm}$ in thickness, with a gauge length of $25 \pm 0.5$ mm [5]. The cyclic stress employed was sinusoidal at a frequency of 2Hz. Eighteen samples were tested in tension - tension with a lower stress of $0.3 \mathrm{MPa}$ and an upper stress of $22 \mathrm{MPa}$, which is representative of the tensile stress range experience within a acrylic bone cement mantle in vivo. All the mechanical testing was conducted in air at $23 \pm 0.5^{\circ} \mathrm{C}$. Each sample was tested until failure and the maximum number of cycles at failure (Nf) was recorded.

The maximum temperature and setting parameters of each bone cement mix were measured in accordance with ISO 5833 (International Standard Organisation 2002). A PTFE mould was used to contain the bone cement during polymerisation, with a nickel/chromium/aluminium k-type thermocouple used to measure the temperatures which 
were recorded using the PicoLog Data Acquisition software package (Pico Technology Ltd, UK) [22]. The mixing system, test equipment and the constituents of the cement were conditioned at $23 \pm 0.5^{\circ} \mathrm{C}$ and at a relative humidity of not less than $40 \pm 1 \%$ for at least $2 \pm$ $0.1 \mathrm{~h}$ before beginning the test. Temperature data were recorded at regular intervals of $1 \mathrm{~s}$ for a time span of 30min. Three bone cement samples were tested for each cement mix.

Porosity content and shrinkage levels within the cement samples were determined. Density measurements were obtained using Archimedes' principle of buoyancy. The bone cement density was measured using an electronic densitometer, a Sartorius LA 620P Toploader scale balance incorporating a YDL01 Density determination kit (Sartorius Ltd, UK). Using Archimedes' principle the apparent loss in weight of a body immersed in fluid, is equal to the weight of fluid displaced. The fluid used was deionised water with a density of 1 $\mathrm{g} \mathrm{cm}^{-3}$. The apparent density of the specimen, $\rho_{\mathrm{a}}$, was calculated using Equation $\mathbf{1 .}$

$$
\rho_{\mathrm{a}}=\left(\frac{\left(\mathrm{m}_{\mathrm{air}} \times \rho_{\text {water }}\right)}{\left(\mathrm{m}_{\text {air }}-\mathrm{m}_{\text {water }}\right)}\right)
$$

Equation 1

As a result of obtaining the apparent density for each of the mixed bone cement samples, it was then possible to calculate percentage porosity (Equation 2) content within the cement samples from knowing the maximum density. The maximum density is the density of the bone cement when it is completely free of pores and voids. The percentage shrinkage of each bone cement specimen was determined using Equation 3, where the effective initial density (maximum density) of the cement is the density after mixing, prior to polymerisation and containing no porosity. The effective initial density (apparent density) was calculated using the constituent details of the polymer powder and liquid monomer. The effective final density is the density of the mixed bone cement after polymerisation. 


$$
\text { Percentage Porosity }=\left(1-\left(\frac{\text { Apparent Density }}{\text { Maximum Density }}\right)\right) * 100
$$

Equation 2

$$
\text { Percentage Shrinkage }=\left(\left(\frac{\text { Effective Initial Density }}{\text { Effective Final Density }}\right)-1\right) * 100
$$

Equation 3

\section{Results}

Compressive strength was significantly affected by the interaction between BPO content and DmpT content, accounting for $21.99 \%$ of the overall contribution. The highest compressive strength was observed when BPO and DmpT were both present at low levels, i.e. BPO:DmpT molar ratio of 1:0.3, recording a compressive strength of 79.96MPa (Figure 1). The interaction between BPO content and powder to liquid ratio accounted for $12.56 \%$ of the overall contribution. Compressive strength was greatest at $81.02 \mathrm{MPa}$, when low BPO content $(0.16 \mathrm{~mL})$ was present with a high powder to liquid ratio $(1.20 \mathrm{~g} / \mathrm{mL})$. Polymer MW also played a significant role accounting for $25.52 \%$ of the overall contribution. Increasing polymer MW from $80 \mathrm{k}$ to $120 \mathrm{k} \mathrm{g} / \mathrm{mol}$ increased the compressive strength from $72.26 \mathrm{MPa}$ to 82.17MPa. The interaction between polymer MW and BPO content attributed to $23.59 \%$ of the overall contribution. Compressive strength was greatest (83.48MPa) when a low BPO content $(0.16 \mathrm{~mL})$ was present with a high polymer MW of $120 \mathrm{~kg} / \mathrm{mol}$.

Polymer MW had a significant effect in the bending strength of the material, attributing to $14.79 \%$ of the overall contribution. An increase in MW from $80 \mathrm{k}$ to $120 \mathrm{k} \mathrm{g} / \mathrm{mol}$ increased the bending strength from 46.95MPa to 54.87MPa (Figure 2). Bending strength was greatest at $55.36 \mathrm{MPa}$, when the $\mathrm{BPO}$ was present at low levels of $0.82 \mathrm{~g}$, accounting for 
17.98\% of the overall contribution. A similar trend was observed for DmpT content, which accounted for $26.58 \%$ of the overall contribution. Increasing the DmpT content from 0.16 to 3.92mL decreased the bending strength from 56.41MPa to $44.55 \mathrm{MPa}$. The mixing time of the two-paste components also had a significant effect, attributing to $15.92 \%$ of the overall contribution. Bending strength increased from $45.89 \mathrm{MPa}$ to $55.07 \mathrm{MPa}$ when the mixing time was increased from $6 \mathrm{~h}$ to $18 \mathrm{~h}$. The powder MW accounted for $44.75 \%$ of the overall contribution. Increasing the powder MW from $80 \mathrm{k}$ to $120 \mathrm{k} \mathrm{g} / \mathrm{mol}$ resulted in an increase in the bending modulus from $2330.71 \mathrm{MPa}$ to $3244.99 \mathrm{MPa}$. However is must be noted that at both high and low levels of powder MW, the bending modulus was above the minimum required level as prescribed by ISO guidelines (ISO 5833:2002) of 1800MPa. The interaction between powder MW and powder to liquid ratio also had a significant effect, accounting for $12.87 \%$ of the overall contribution. Bending modulus was greatest, $3639.31 \mathrm{MPa}$, when a high powder MW of $120 \mathrm{k} \mathrm{g} / \mathrm{mol}$ was present with a high powder to liquid ratio of $1.20 \mathrm{~g} / \mathrm{mL}$. The interacting levels of powder MW and powder to liquid ratio resulted in the bending modulus recorded being above the minimum acceptable levels quoted by ISO 5833:2002.

Observing the thermal properties, the maximum exothermic temperatures recorded during polymerisation were significantly affected by BPO content, attributing to $30.53 \%$. Decreasing BPO levels from 4.51 to $0.82 \mathrm{~g}$ decreased the maximum exothermic temperature from 73.62 to $62.05^{\circ} \mathrm{C}$. It must be noted that at both high and low levels of BPO the maximum exothermic temperatures were below the maximum threshold levels quoted by ISO 5833:2002 (i.e. $<90^{\circ} \mathrm{C}$ ). The interaction between BPO and DmpT also had a significant affect attributing to $25.66 \%$ of the overall contribution. The lowest exothermic temperatures were recorded when a low level of BPO at $0.82 \mathrm{~g}$ was present with a high level of DmpT at 3.92mL (Figure 3), however it was observe that for all levels of BPO and DmpT interaction the exothermic temperatures were below $90{ }^{\circ} \mathrm{C}$ as stated in ISO 5833 (International Standard 
Organisation 2002). The setting times were significantly affected by BPO content accounting for $16.90 \%$ of the overall contribution. Increasing the BPO content from 0.82 to $4.51 \mathrm{~g}$ decreased the setting time from 18.24 to $7.58 \mathrm{~min}$. DmpT accounted for $49.81 \%$ of the overall contribution showing that an increase in the DmpT content from 0.16 to $3.92 \mathrm{~mL}$ decreased the setting time from 22.05 to $3.77 \mathrm{~min}$.

Powder MW significantly affected the mean fatigue performance with a contribution of $20.78 \%$. Increasing powder MW from $80 \mathrm{k}$ to $120 \mathrm{k} \mathrm{g} / \mathrm{mol}$ resulted in an increase in the mean fatigue cycles from 775 to 2213 cycles to failure. Powder to liquid ratio accounted for $10.19 \%$, illustrating that a decrease in powder to liquid ratio from 1.20 to $0.80 \mathrm{~g} / \mathrm{mL}$ increased the mean fatigue cycles from 797 to 1922 cycles. Mixing time had a $10.00 \%$ contribution in terms of the mean number of fatigue cycles recorded. An increase in mixing time from $6 \mathrm{~h}$ to 18h increased the mean number of fatigue cycles to failure from 802 to 1917 cycles. Three interactions of factors had a significant effect on the mean number of fatigue cycles to failure. The interaction between powder MW and mixing time accounted for a $15.94 \%$ contribution. The mean number of fatigue cycles recorded was highest (3015 cycles) when a high level of mixing (18hr) was present with a high powder MW (120k g/mol) (Figure 4). The interaction between powder to liquid ratio and mixing time accounted for $14.66 \%$ of the overall contribution. A high mixing time of $18 \mathrm{~h}$ with a low powder to liquid ratio of $0.80 \mathrm{~g} / \mathrm{mL}$ resulted in a mean number of fatigue cycles to failure of 3155 cycles. The interaction between BPO and DmpT content also played a significant role, attributing to $15.39 \%$ of the overall contribution. The mean number of fatigue cycles to failure was highest (2280 cycles) when a high level of BPO (4.51g) was present with a low level of DmpT (0.16mL).

The porosity content was significantly affected by BPO content, attributing to $10.97 \%$ of the overall contribution. As the BPO content decreased from 4.51 to $0.82 \mathrm{~g}$, the porosity content decreased from 6.76 to $5.66 \%$. Mixing time attributed to $22.78 \%$ of the overall 
contribution showing that an increase in mixing time from 6 to $18 \mathrm{~h}$ resulted in a decrease in porosity content from 7.00 to $5.42 \%$. The interaction between powder to liquid ratio and DmpT attributed $27.73 \%$ of the overall contribution. The lowest porosity level (4.81\%) was recorded when a low level of BPO $(0.82 \mathrm{~g})$ was present with a low powder to liquid ratio $(0.80 \mathrm{~g} / \mathrm{mL})$. The interaction between powder to liquid ratio and mixing time also had a significant effect at $10.48 \%$ of the overall contribution. Porosity content was lowest at a high powder to liquid ratio $(1.20 \mathrm{~g} / \mathrm{mL})$ and a high mixing time (18 h) (Figure 5). It can also be observed that at a high mixing time and a low powder to liquid ratio only resulted in a porosity increase of $0.81 \%$.

BPO content had a significant effect on the shrinkage level with a $10.97 \%$ contribution. Decreasing the BPO content from 4.51 to $0.82 \mathrm{~g}$ resulted in a reduction in the shrinkage level from 7.32 to $6.06 \%$ (Figure 6). Mixing time had a significant influence at $22.78 \%$, indicating that an increase in mixing time from 6 to $18 \mathrm{~h}$ decreased the shrinkage level from 7.59 to 5.79\% (Figure 7). The interaction between powder to liquid ratio and DmpT content accounted for $27.73 \%$ of the overall contribution. The shrinkage level was lowest $(5.08 \%)$ when a low powder to liquid ratio of $0.80 \mathrm{~g} / \mathrm{mL}$ was present with a low level of DmpT $(0.16 \mathrm{~mL})$. The interaction between powder to liquid ratio and mixing time accounted for $10.48 \%$ of the overall contribution. The shrinkage level was lowest at a high powder to liquid ratio of $1.20 \mathrm{~g} / \mathrm{mL}$ and a high mixing time of $18 \mathrm{~h}$. As was the case with the porosity, it can also be noted that at a high mixing time and a low powder to liquid ratio only resulted in an increase in shrinkage level of $0.13 \%$.

\section{Discussion}

As polymer MW increased from $80 \mathrm{k}$ to $120 \mathrm{k} \mathrm{g} / \mathrm{mol}$, the mechanical properties increased. The compressive strength, bending strength and bending modulus increased from 72.2682.17 MPa, 46.95-54.87 MPa and 2330-3244 MPa respectively. The mean number of fatigue 
cycles to failure increased form 775-2213 cycles. Weight average MW can be characterised as the length of the polymer chains in the initial polymer powder or the resultant polymerised bone cement. Haas et al (1975) reported an improvement in mechanical performance with increasing MW. A higher weight average MW for the pre-polymerised powder will result in the formation of longer polymer chains and therefore an increased average MW of the polymerised bone cement. The improved mechanical performance of the bone cement is mostly due to an increase in the average MW of the overall material, which decreases the number of chains ends and the molecular motion [23] [24].

The component mixing time during cement preparation had a significant effect on both the bending strength and fatigue properties. This factor also had a prominent effect on the porosity content and shrinkage level for the cured cement. This effect of increasing the mixing time decreased the porosity content and shrinkage levels within the cement. Increasing the mixing time during the cement preparation can lead to increased homogeneity as a result of better interactions between the powder and liquid constituents in the respective barrels. It is important during the mixing phase to avoid in-homogeneities within the cement to ensure that there is uniform polymerisation and no variation in the final properties of the cement. Walker et al (2008) demonstrated improved cement performance using an automated mixer when compared to a manual mixing regime. They concluded that the increase cement performance was largely due to improved homogeneity in the cement when controlled, repeatable mixing was adopted.

With respect to the mechanical properties, it was observed that increased mixing time had a positive effect on mechanical performance. This can be directly related to a reduction in the cement porosity and consequently the shrinkage levels exhibited post polymerisation. A decrease in the porosity content within the cement microstructure will result in fewer crack initiation sites. It has previously been reported that mixing cement using a bowl and spatula 
arrangement produces an inhomogeneous cement mix containing a high porosity content [25]. A high powder - liquid homogeneity during cement mixing could improve the overall mechanical performance. Several studies have shown that the success of the cement mix can be dependent on the porosity content. Dunne and Orr (2001) reported a reduction in the porosity content depending on the cement mixing and delivery system used; they concluded that voids within the cement acted as stress raisers, leaving the cement susceptible to failure [3]. Lidgren et al also reported that the application of vacuum during cement mixing led to a reduction in porosity and consequently an increase in the mechanical performance of the resultant cement [4].

Bone cement shrinkage that occurs during polymerisation can have a detrimental effect on the mechanical performance. In this study, a reduction in shrinkage level was observed when the mixing time was increased. During the polymerisation process, the MMA liquid is converted to PMMA solid resulting in a volume change, which leads to a decrease in cement volume and as a result shrinkage occurs. Although every effort was made to ensure full dissolution of the PMMA powder in the MMA monomer, the increased levels of cement shrinkage due to the use of a lesser mixing time could be as a result of reduced dissolution of PMMA into MMA, therefore the MMA is available in larger quantities during polymerisation. Shrinkage has been implicated in introducing residual stressing during the polymerisation process, resulting in the formation of cracks and decreased mechanical performance [16] [26]. This study has shown that increased mixing time can reduced the cement shrinkage and as a direct consequence increasing the bending and fatigue performance.

The presence of initiation chemistry within the cement will have an effect on the final properties; the significance of the effect will depend on the BPO: DmpT ratio [6] [27]. The results from this study have shown that the presence of initiation chemistry had a significant 
effect on the mechanical properties. The highest compressive strength was recorded for both low levels of BPO and DmpT at 79.96MPa, however there was approximately $1 \%$ reduction in compressive strength when both high levels of BPO and DmpT were present. The powder to liquid ratio was lower (i.e. 0.8:1 and 1.2:1) for the pre-filled mixing and delivery system when compared to the 2:1 powder to liquid ratio used during conventional bone cement preparation. A lower powder to liquid ratio was required to ensure the two-paste components flowed more readily through the static mixer nozzle. High MMA availability together with high levels of BPO and DmpT will result in a higher number of initiating radicals, which will result in shorter chains. However an increase in the crosslinking density will result in an increase in mechanical performance of the bone cement. Hasenwinkel et al (1999) showed that BPO and DmpT available in equal molar quantities to lead to a higher yield, increasing MMA conversion and a higher MW cement being produced. Studies have shown that an increase in cement density will result in higher levels of compressive strength and bending strength of acrylic bone cement [3]. Although this was the case for compressive properties, the bending strength was increased when BPO and DmpT were present at low levels. This could be as a result of lower porosity content and cement shrinkage being observed for lower levels of BPO and DmpT. Decreased porosity and shrinkage will reduce the occurrence of crack initiation sites and therefore the induction of residual stresses [5] [16].

The fatigue performance was significantly affected by the powder to liquid ratio used. A decrease in the powder to liquid ratio from 1.20 to $0.80 \mathrm{~g} / \mathrm{mL}$ increased the fatigue performance of the cement. As previously noted increasing the mixing time enhanced the fatigue performance. Fatigue performance was also significantly affected by the interaction between powder to liquid ratio and mixing time, with better fatigue properties being demonstrated when both an increased mixing time and low powder to liquid ratio were present. Analysis of the porosity and cement shrinkage showed that decreasing the powder to 
liquid ratio and increasing mixing time resulted in reduced porosity and cement shrinkage being observed. This enhancement in the fatigue performance is as a result of reducing the availability of sites for crack propagation and the induction of residual stress leading to improved mechanical performance [5] [16].

In terms of thermal properties, the maximum exothermic temperature was significantly affected by the interaction between BPO and DmpT along with independent BPO content. BPO - DmpT interaction and independent BPO levels had a 25.66\% and $30.53 \%$ contribution to the maximum temperature. During polymerisation, chain propagation takes place by cleaving BPO and generating free radicals and it is these free radicals that react with unsaturated carbons, i.e. $\mathrm{C}=\mathrm{C}$ of monomer, and leave with another free radical, which is a chain process until the termination step occurs. The rate of the reaction depends on $\mathrm{BPO}$ and the energy released is in the form of heat. It has been reported that the energy released during polymerisation is between $54-57 \mathrm{~kJ}$ of energy per mole of MMA monomer [12] [28]. Results showed that lower temperatures exhibited during the exothermic polymerisation reaction were as a result of low BPO levels and high DmpT levels. With low levels of BPO present there was a limited availability to combine with DmpT, resulting in the formation of less free radicals, therefore less energy released and lower temperatures observed.

The setting times were significantly affected by independent BPO and DmpT levels Increasing both BPO and DmpT levels decreased the setting time of the cement. During the polymerisation reaction, DmpT combines with BPO, causing the BPO to decompose. This decomposing process forms benzoyloxy radicals, which combine with the MMA to form active centres allowing multiple monomer chains to form, starting cement polymerisation. If DmpT is present at higher levels, more or all of the BPO can be decomposed, allowing 
multiple monomer chains to grow simultaneously. This in effect allows the polymerisation reaction to happen at a faster rate, thereby reducing the setting time [28] [29].

Following analysis of the effects of the different factors investigated on the parameters analysed, the DoE software package was used to determine the optimum cement mixing and delivery properties. The DoE software was then able to analyse the data gathered from the randomised experimental mixes and determine the optimum combination to meet the desired material properties. The optimum composition determined by the DoE is shown in Table 2. Within addition to determining the optimum composition, DoE can also be used to predict the theoretical results that the parameters should meet upon testing. The optimum composition was prepared, the resultant cement analysed and the relevant properties determined. The results obtained were then used to corroborate the optimum recipe and DoE as an approach for optimising the bone cement mixing and delivery method. The experimental results for the analysed optimum cement mix composition are shown in Table 3.

The results for the optimum bone cement formulation and mixing conditions demonstrated that the compressive strength measured experimentally was $84.77 \pm 8.56 \mathrm{MPa}$ compared to 79.38MPa predicted by DoE. Experimental analyses of bending strength was $61.21 \pm 10.25 \mathrm{MPa}$ and bending modulus $3207.77 \pm 331.47 \mathrm{MPa}$ compared with $58.44 \mathrm{MPa}$ and 2932.46 MPa predicted by DoE respectively. Thermal analyses resulted in a maximum exotherm of $85.93 \pm 1.52{ }^{\circ} \mathrm{C}$ and a setting time of $1.56 \pm 0.54$ min when compared with $67.84{ }^{\circ} \mathrm{C}$ and 12.00 min predicted by DoE respectively. The fatigue properties predicted by DoE was a mean of 4,578 fatigue cycles; experimentally the value was 11,064 \pm 5,255 mean fatigue cycles. Porosity levels with the optimum composition were predicted to be $6.05 \%$ and showed experimentally to be $5.92 \pm 1.18 \%$. The shrinkage levels experimentally recorded were $6.31 \pm 1.34 \%$, compared to $6.54 \%$ as predicted by DoE. 
It is noted that a variation is present in the results predicted when compared to those obtained during experimental analyses. This is expected because the DoE does not take into account the effect of factors which are insignificant to the parameters analysed, although when combined can result in variation. A problem with attempting to optimize a material such as acrylic bone cement is that the polymerisation reaction is complex with a number of processes happening simultaneously; a change to improve one parameter may lead to a negative effect on another [30].

\section{Conclusion}

This study was conducted to obtain a better understanding of the factors that have a significant impact on mixing and delivery of different formulations of acrylic bone cement using a pre-filled mixing and delivery system. The DoE illustrated that all factors had a significant impact on the final properties of the cement. Experimentally the optimum recipe demonstrated mechanical and thermal properties in agreement with the clinical guidelines acceptable for total joint replacement surgery as stated in ISO 5833:2002. However, when considering setting times, the optimum recipe experimentally produced setting times of 1.56 \pm 0.54 min compared to 12.00 min predicted by the DoE. This low setting time would not be clinically viable and could result in complications during the surgical technique. As a result further development would be required to improve the setting time of the cement in order for it to be deemed suitable for use in total joint replacement surgery. 


\section{References}

[1] K. Dang, M. H. Pelletier, and W. R. Walsh, 'Factors Affecting Flexural Strength in Cement Within Cement Revisions', The Journal of Arthroplasty, vol. 26, no. 8, pp. 1540-1548, Dec. 2011.

[2] R. J. Kane, W. Yue, J. J. Mason, and R. K. Roeder, 'Improved fatigue life of acrylic bone cements reinforced with zirconia fibers', Journal of the Mechanical Behavior of Biomedical Materials, vol. 3, no. 7, pp. 504-511, Oct. 2010.

[3] N. Dunne and J. Orr, 'Influence of mixing techniques on the physical properties of acrylic bone cement', Biomaterials, vol. 22, no. 13, pp. 1819-1826, 2001.

[4] L. Lidgren, H. Drar, and J. Möller, 'Strength of polymethylmethacrylate increased by vacuum mixing', Acta Orthop, vol. 55, no. 5, pp. 536-541, Jan. 1984.

[5] N. Dunne, J. Orr, M. Mushipe, and R. Eveleigh, 'The relationship between porosity and fatigue characteristics of bone cements', Biomaterials, vol. 24, no. 2, pp. 239-245, Jan. $\underline{2003 .}$

[6] J. M. Hasenwinkel, E. P. Lautenschlager, W. L. Richard, and J. L. Gilbert, 'Effect of initiation chemistry on the fracture toughness, fatigue strength, and residual monomer content of a novel high-viscosity, two-solution acrylic bone cement', Journal of Biomedical Materials Research, no. 59, pp. 411-421, 2002.

[7] D. Hoey and D. Taylor, 'Quantitative analysis of the effect of porosity on the fatigue strength of bone cement’, Acta Biomaterialia, vol. 5, no. 2, pp. 719-726, Feb. 2009.

[8] A. R. Eriksson and T. Albrektsson, 'Temperature threshold levels for heat-induced bone tissue injury: A vital-microscopic study in the rabbit', The Journal of Prosthetic Dentistry, vol. 50, no. 1, pp. 101-107, Jul. 1983.

[9] N. Dunne and J. Orr, 'Thermal characteristics of curing acrylic bone cement', ITBMRBM, vol. 22, no. 2, pp. 88-97, Apr. 2001.

[10] K. Kuehn, W. Ege, and U. Gopp, 'Acrylic bone cements: composition and properties', Orthop Clin North Am, vol. 36, no. 1, pp. 17-28, Jan. 2005.

[11] BS ISO 5833:2002, ‘Implants for Surgery - Acrylic resin cements’. 2002.

[12] P. R. Meyer, E. P. Lautenschlager, and B. K. Moore, 'On the setting properties of acrylic bone cement', Journal of Bone \& Joint Surgery, vol. 55, no. 1, pp. 149-156, $\underline{1973 .}$

[13] R. C. Turner, F. B. White, and J. B. Park, 'The effect of initial temperature on free radical decay in PMMA bone cement', J Biomed Mater Res., vol. 16, no. 5, pp. 639$\underline{646,1982 .}$ 
[14] R. E. Turner, P. E. Atkins, M. A. Ackley, and J. B. Park, 'Molecular and macroscopic properties of PMMA bone cement: Free-radical generation and temperature change versus mixing ratio', J Biomed Mater Res, vol. 15, pp. 425-432, 1981.

[15] C. I. Vallo, P. E. Montemartini, and T. R. Cuadrado, 'Effect of residual monomer content on some properties of a poly9methyl methacrylate)-based bone cement', J Appl Polym Sci, vol. 69, no. 7, pp. 1367-1383, 1998.

[16] J. Orr, N. Dunne, and J. Quinn, 'Shrinkage stresses in bone cement', Biomaterials, vol. 24, no. 17, pp. 2933-2940, Aug. 2003.

[17] J. Gilbert, J. Hasenwinkel, R. Wixson, and E. Lautenschlager, 'A theoretical and experimental analysis of polymerization shrinkage of bone cement: A potential major source of porosity', J Biomed Mater Res, vol. 52, no. 1, pp. 210-218, Oct. 2000.

[18] A. López, E. Unosson, H. Engqvist, and C. Persson, 'Direct and interactive effects of three variables on properties of PMMA bone cement for vertebral body augmentation' $\mathrm{J}$ Mater Sci Mater Med, vol. 22, no 6, pp. 1599-606, 2011.

[19] D. M. I. Werdofa, and G. Lewis, 'Direct and interactive influence of explanatory variables on properties of a calcium phosphate cement for vertebral body augmentation', J Mater Sci. Mater Med. vol. 25, no. 1, pp. 55-66, Jan 2014.

[20] R. M. O’Hara, N. J. Dunne, J. F. Orr, F. J. Buchanan, R. K. Wilcox, D. C. Barton, 'Optimisation of the mechanical and handling properties of an injectable calcium phosphate cement', Journal of Materials Science: Materials in Medicine, vol. 21, no. 8, pp. 2299-2305, August 2010.

[21] E. J. Harper, and W. Bonfield, 'Tensile characteristics of ten commercial acrylic bone cements', J. Biomed. Mater. Res., vol. 53, pp. 605-616, 2000.

[22] N. J. Dunne and J. F. Orr, 'Curing characteristics of acrylic bone cement', Journal of Materials Science: Materials in Medicine, vol. 13, no. 1, pp. 17-22, Jan. 2002.

[23] G. Lewis, 'Relative roles of cement molecular weight and mixing method on the fatigue performance of acrylic bone cement: Simplex ${ }^{\circledR P}$ versus Osteopal®', J. Biomed. Mater. Res., vol. 53, no. 1, pp. 119-130, Jan. 2000.

[24] E. J. Harper, M. Braden, W. Bonfield, E. Dingeldein, and H. Wahlig, 'Influence of sterilisation upon a range of properties of experimental bone cements', Journal of Materials Science: Materials in Medicine, vol. 8, pp. 849-853, 1997.

[25] H. Lelovics and T. Liptakova, 'Time and mixing technique dependent changes in bone cement smartset', Acta of Bioengineering and Biomechanics, vol. 12, no. 4, pp. 63-67, $\underline{2010 .}$

[26] A. Lennon and P. . Prendergast, 'Residual stress due to curing can initiate damage in porous bone cement: experimental and theoretical evidence', Journal of Biomechanics, vol. 35, no. 3, pp. 311-321, Mar. 2002.

[27] G. Lewis, J. Xu, S. Madigan, and M. Towler, 'Influence of two changes in the composition of an acrylic bone cement on its handling, thermal, physical, and 
mechanical properties.', J Mater Sci Mater Med, vol. 18, no. 8, pp. 1649-1658, Aug. 2007.

[28] K. Kuhn, Bone Cements - Up to Date Comparison of Physical and Chemical Properties of Commercial Materials. Berlin: Springer - Verlag, 2000.

[29] I. Rehman, E. J. Harper, and W. Bonfield, 'In situ analysis of the degree of polymerization of bone cement by using FT-Raman spectroscopy', Biomaterials, vol. 17, no. 16, pp. 1615-1619, 1996.

[30] B. Pascual, B. Vázquez, M. Gurrachaga, I. Goñi, M. P. Ginebra, F. J. Gil, J. A. Planell, B. Levenfeld, and J. S. Román, 'New aspects of the effect of size and size distribution on the setting parameters and mechanical properties of acrylic bone cements', Biomaterials, vol. 17, no. 5, pp. 509-516, 1996. 
Table 1: Factors and Limits for Design of Experiments.

\begin{tabular}{|c|c|c|c|c|}
\hline & Factor & Units & Low & High \\
\hline A & Powder Molecular Weight & $\mathrm{k} \mathrm{g} / \mathrm{mol}$ & 80 & 120 \\
\hline B & Powder to Liquid Ratio & $\mathrm{g} / \mathrm{mL}$ & 0.8 & 1.2 \\
\hline C & BPO Content & g & 0.82 & 4.51 \\
\hline D & DmpT Content & $\mathrm{mL}$ & 0.16 & 3.92 \\
\hline $\mathbf{E}$ & Mixing Time & $\mathrm{h}$ & 6 & 18 \\
\hline
\end{tabular}


Table 2: Optimum Cement Mixing and Delivery Composition.

\begin{tabular}{ccc}
\hline & Factor & Optimum Level \\
\hline A & Polymer Molecular Weight & $120 \mathrm{k} \mathrm{g} / \mathrm{mol}$ \\
B & Powder to Liquid Ratio & $0.80 \mathrm{~g} / \mathrm{mL}$ \\
C & BPO Content & $2.67 \mathrm{~g}$ \\
D & DmpT Content & $2.23 \mathrm{~mL}$ \\
E & Mixing Time & $18.00 \mathrm{~h}$ \\
\hline
\end{tabular}


Table 3: Theoretical and Experimental Values for Optimum Recipe Composition as Produced by DoE.

\begin{tabular}{lcc}
\hline \multicolumn{1}{c}{ Parameter } & $\begin{array}{c}\text { Theoretical } \\
\text { Prediction }\end{array}$ & Experimental Results \\
\hline Compressive Strength (MPa) & 79.38 & $84.77 \pm 8.56$ \\
Bending Strength (MPa) & 58.44 & $61.21 \pm 10.25$ \\
Bending Modulus (MPa) & 2932.46 & $3207.77 \pm 331.47$ \\
Fatigue Mean (cycles) & 4578 & $11064 \pm 5255$ \\
Max Exothermic Temperature $\left({ }^{\circ} \mathbf{C}\right)$ & 67.84 & $85.93 \pm 1.52$ \\
Setting Time (min) & 12.00 & $1.56 \pm 0.54$ \\
Porosity (\%) & 6.05 & $5.92 \pm 1.18$ \\
Shrinkage (\%) & 6.54 & $6.31 \pm 1.34$ \\
\hline
\end{tabular}




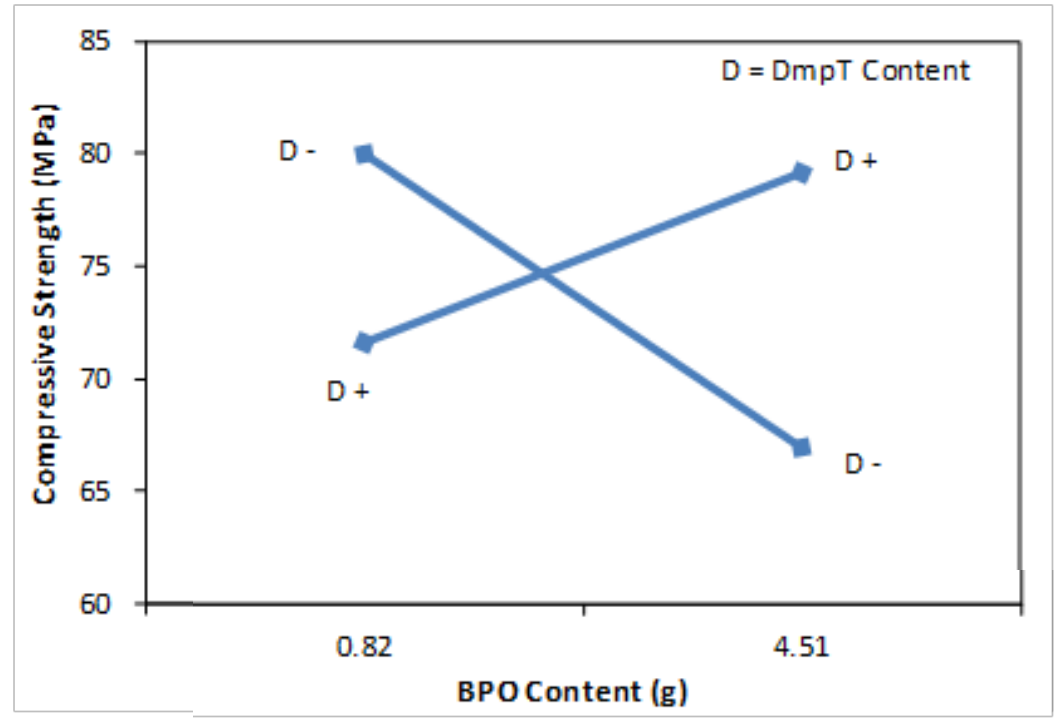

Figure 1: Extent of Interaction between BPO content and DmpT Content on Compressive Strength. Note molar ratio between BPO and DmpT is: Low BPO: High DmpT = 1:8; Low BPO: Low DmpT = 1:0.3; High BPO: High DmpT = 1:1.4: High BPO: Low DmpT = 1:0.6. 


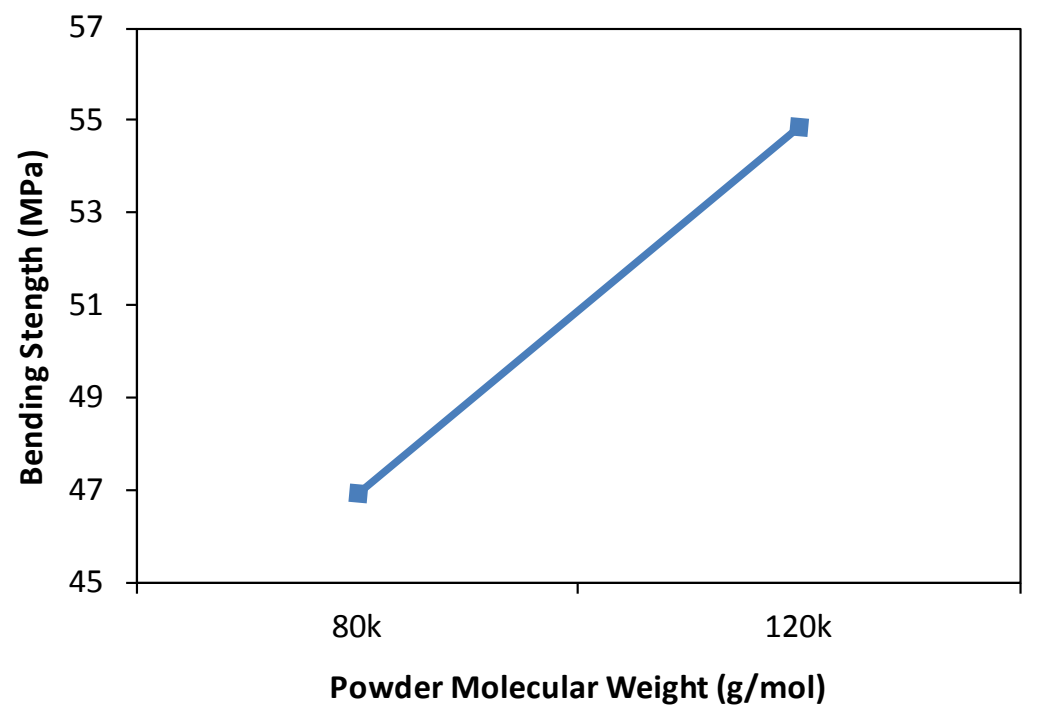

Figure 2: Effect of Powder weight average MW on Bending Strength. 


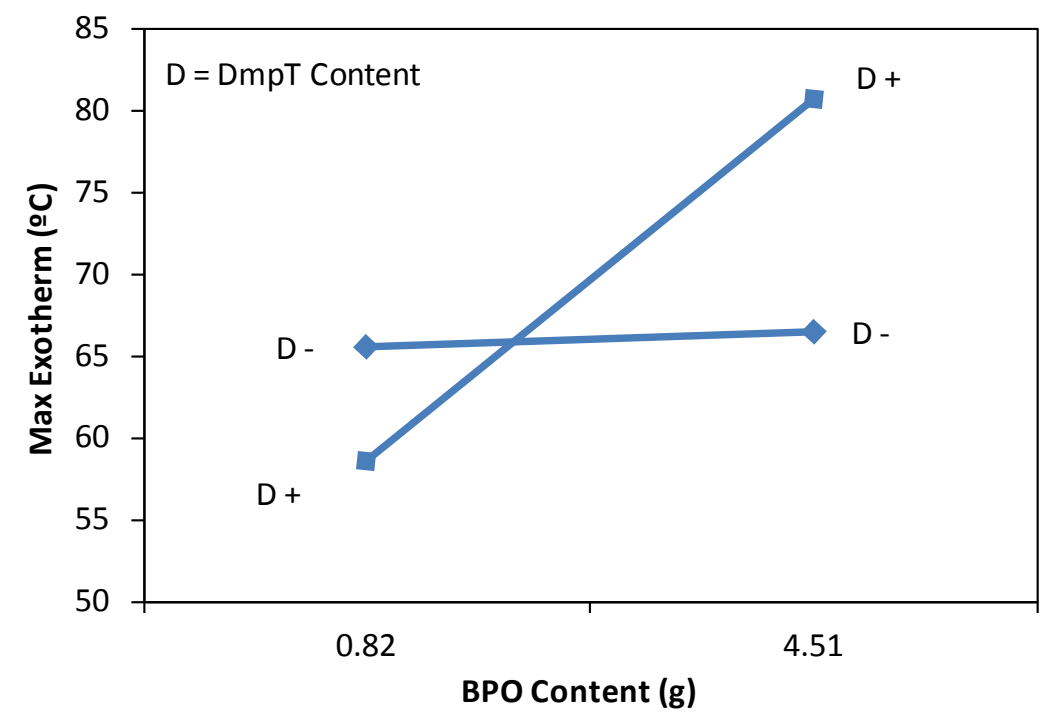

Figure 3: Extent of Interaction between BPO content and DmpT Content on Maximum Exothermic Temperature. Note molar ratio between BPO and DmpT is: Low BPO: High DmpT = 1:8; Low BPO: Low DmpT = 1:0.3; High BPO: High DmpT = 1:1.4: High BPO: Low DmpT = 1:0.6. 


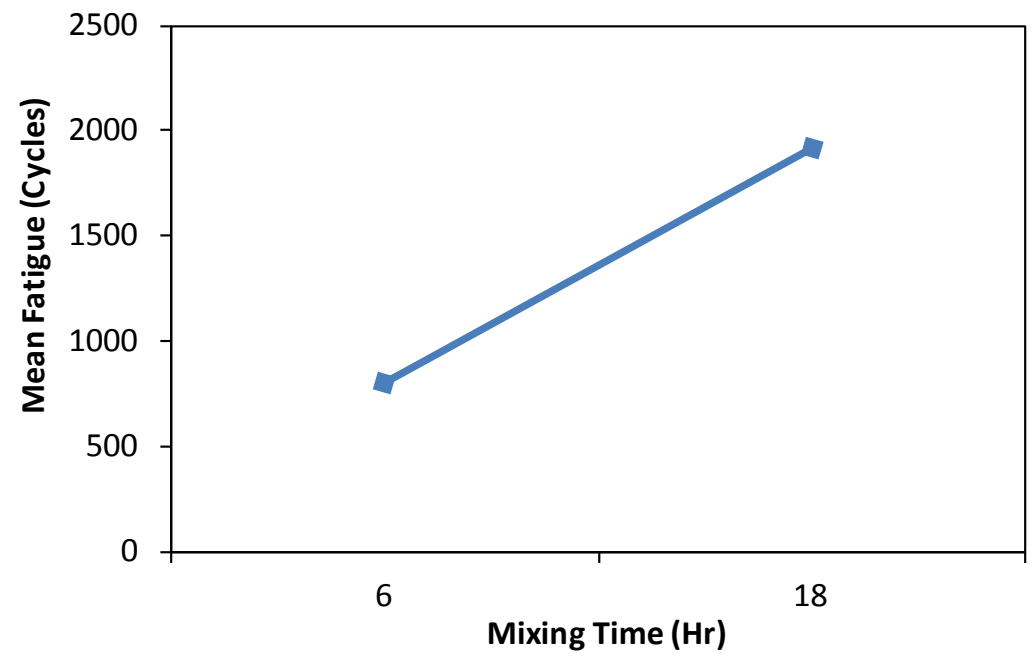

Figure 4: Effect of Mixing Time on Mean Number of Fatigue Cycles to Failure. 


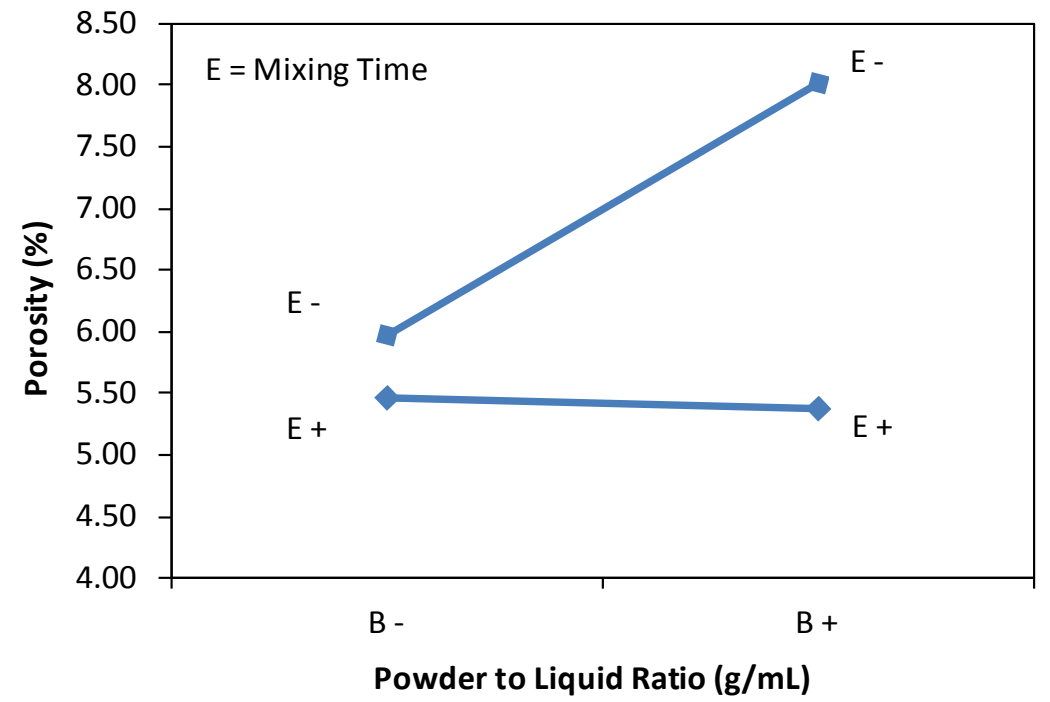

Figure 5: Extent of Interaction between Powder to Liquid Ratio and Mixing Time on Porosity. 


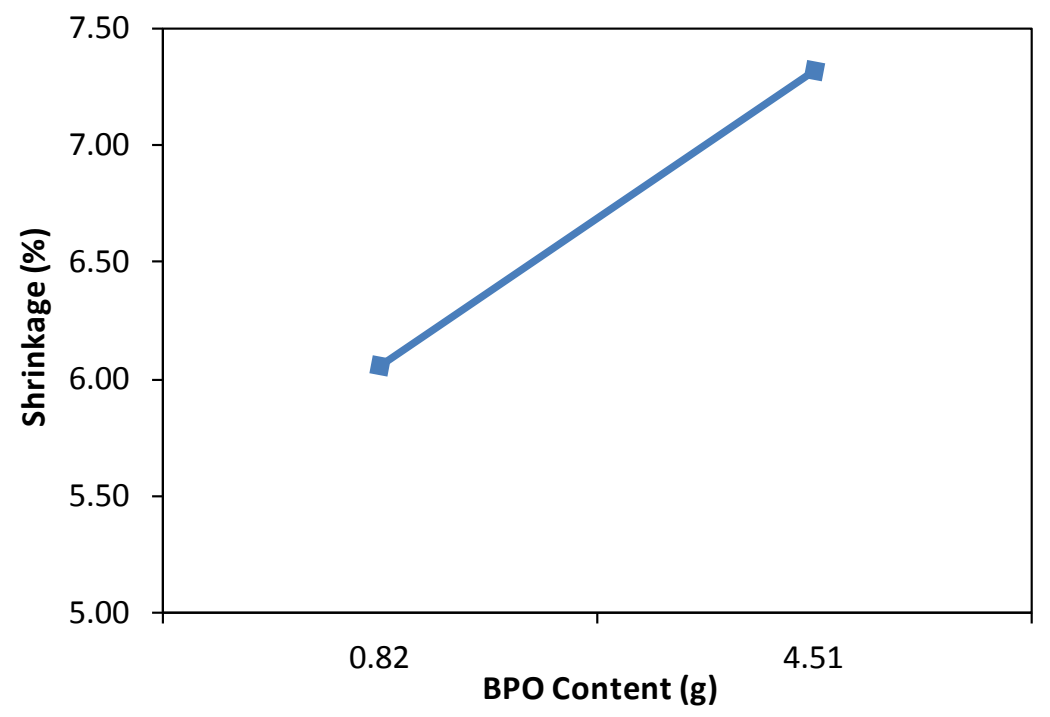

Figure 6: Effect of BPO Content on Porosity. 


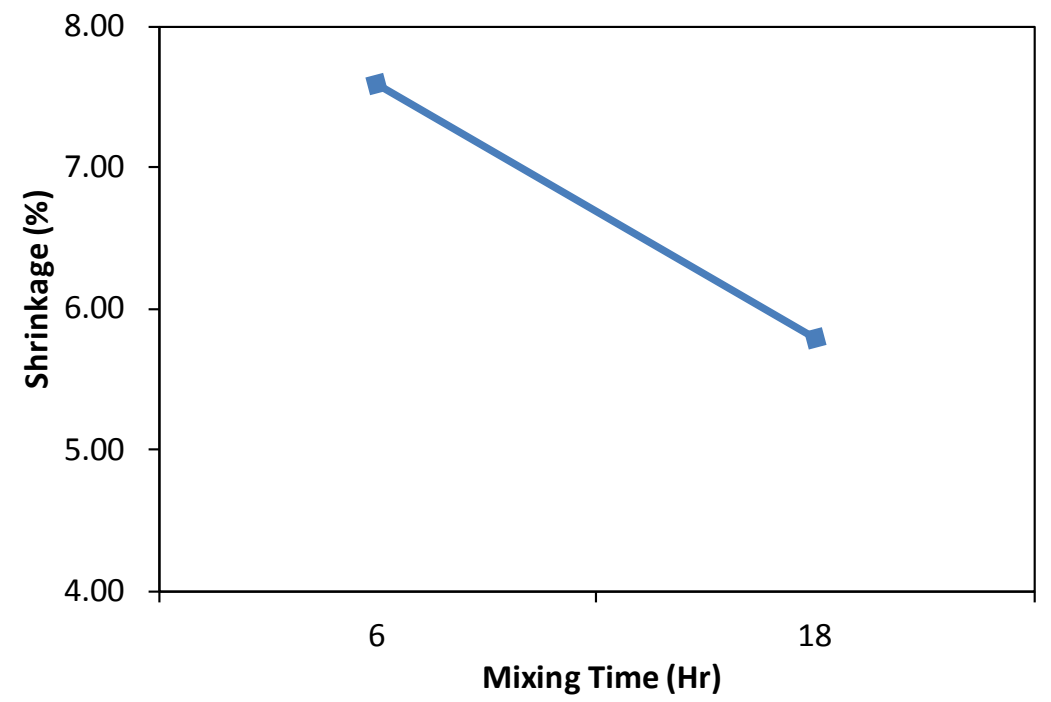

Figure 7: Effect of Mixing Time on Shrinkage. 